\title{
Observational study of the effect of obesity on lung volumes
}

\author{
Joerg Steier, ${ }^{1,2}$ Alan Lunt, ${ }^{1}$ Nicholas Hart, ${ }^{1,2}$ Michael I Polkey, ${ }_{1}^{3}$ John Moxham ${ }^{1}$
}

\begin{abstract}
- Additional material is published online only. To view please visit the journal online (http://dx.doi.org/10.1136/ thoraxjnl-2014-205148).

${ }^{1}$ King's College London School of Medicine, King's Health Partners, King's College Hospital, London, UK ${ }^{2}$ Lane Fox Unit, Sleep Disorders Centre, Guy's \& St Thomas' NHS Foundation Trust, London, UK

${ }^{3} \mathrm{NIHR}$ Respiratory Biomedical Research Unit, The Royal Brompton Hospital and Imperial College, London, UK
\end{abstract}

\section{Correspondence to}

Dr Joerg Steier,

Lane Fox Respiratory Unit, Sleep Disorders Centre, Guy's \& St Thomas' NHS Foundation Trust, Westminster Bridge Road, London SE1 7EH, UK; joerg.steier@gstt.nhs.uk

Received 17 January 2014 Revised 12 March 2014 Accepted 18 March 2014 Published Online First 15 April 2014

\begin{abstract}
Background Severe obesity causes respiratory morbidity and mortality. The impact of obesity on the mechanics of breathing is not fully understood.

Patients and methods We undertook a

comprehensive observational study of lung volumes and elasticity in nine obese and nine normal weight subjects, seated and supine, during spontaneous breathing. Seated and supine total lung capacity (TLC) and subdivisions were measured by multibreath helium dilution method. Using balloon catheters, oesophageal (Poes) and gastric (Pgas) pressures were recorded. Transpulmonary pressure $\left(P_{L}\right)$ was calculated as mouth pressure (Pmouth)-Poes, and complete expiratory $P_{L}$ volume curves were measured.
\end{abstract}

Results The obese group had a body mass index (BMI) of $46.8(17.2) \mathrm{kg} / \mathrm{m}^{2}$, and the normal group had a BMI of $23.2(1.6) \mathrm{kg} / \mathrm{m}^{2}(p=0.001)$. Obese and normals were matched for age $(p=0.233)$, gender $(p=0.637)$ and height $(p=0.094)$. The obese were more restricted than the normals (TLC 88.6 (16.9) vs $104.4(12.3) \%$ predicted, $\mathrm{p}=0.033 ; \mathrm{FEV}_{1} / \mathrm{FVC} 79.6$ (7.3) vs 82.5 (4.2) $\%, p=0.325)$, had dramatically reduced expiratory reserve volume (ERV $0.4(0.4)$ vs $1.7(0.6) L, p<0.001$ ) and end-tidal functional residual capacity (FRC) was smaller (37.5 (6.9) vs 46.9 (4.6) \%TLC, $\mathrm{p}=0.004$ ) when seated, but was similar when supine (39.4 (7.7) vs 41.5 (4.3) \%TLC, $p=0.477)$. Gastric pressures at FRC were significantly elevated in the obese (seated 19.1 (4.7) vs $12.1(6.2) \mathrm{cm} \mathrm{H}_{2} \mathrm{O}, \mathrm{p}=0.015$; supine 14.3 (5.7) vs 7.1 (2.6) $\left.\mathrm{cm} \mathrm{H}_{2} \mathrm{O}, p=0.003\right)$, as were end-expiratory oesophageal pressures at FRC (seated 5.2 (6.9) vs -2.0 (3.5) $\mathrm{cm} \mathrm{H}_{2} \mathrm{O}, \mathrm{p}=0.013$; supine 14.0 (8.0) vs 5.4 (3.1) $\left.\mathrm{Cm} \mathrm{H}_{2} \mathrm{O}, \mathrm{p}=0.008\right)$. BMI correlated with end-expiratory gastric (seated $R^{2}=0.43$, supine $R^{2}=0.66, p<0.01$ ) and oesophageal pressures (seated $R^{2}=0.51$, supine $R^{2}=0.62, p<0.01$ ).

Conclusions Obese subjects have markedly increased gastric and oesophageal pressures, both when upright and supine, causing dramatically reduced FRC and ERV, which increases work of breathing.

\section{INTRODUCTION}

The huge increase in obesity in recent decades requires urgent public health strategies for adults ${ }^{1-3}$ and children ${ }^{4}$ and a better understanding of the abnormalities of breathing by those caring for obese patients. From a respiratory perspective, it is accepted that compared with subjects with normal weight, obese subjects can have a reduced total lung capacity (TLC) ${ }^{5}$ and breathe at a lower functional residual capacity (FRC). ${ }^{7-10}$ Obesity increases work of breathing, neural respiratory

\section{Key messages}

What is the key question?

- Obesity is associated with changes of lung volumes, but the physiological origin of this is unknown.

\section{What is the bottom line?}

- The main abnormalities in obesity are the transmission of the high pressures in the intra-abdominal compartment to the thorax that dramatically reduce functional residual capacity and expiratory reserve volume and oblige patients to breathe on a flatter, less efficient, part of their pressure-volume curve, increasing the work of breathing.

\section{Why read on?}

- This comprehensive study, for the first time, measures the entire expiratory pressure-volume curve in spontaneously breathing and non-sedated obese subjects, explaining the increased work of breathing and analysing the relationship between intra-abdominal pressures and altered lung volumes.

drive, ${ }^{11}{ }^{12}$ breathlessness, ${ }^{13}$ causes sleep-disordered breathing and eventually hypercapnic respiratory failure. $^{71415}$ However, the details of the abnormal underlying pulmonary mechanics remain to be elucidated.

Changes in lung volumes with posture are important. ${ }^{16-19}$ In normal subjects, FRC falls when changing from the seated to the supine posture. In contrast, obese subjects, ${ }^{8}$ who breathe closer to residual volume (RV) when seated, may reach closing volume of the airways, and FRC may not decrease further with recumbency. ${ }^{20}{ }^{21}$ Obese subjects can develop intrinsic positive end-expiratory pressure (PEEPi), ${ }^{22}{ }^{23}$ and some have a higher threshold inflation airway pressure. ${ }^{23} \mathrm{~A}$ study by Pelosi et $a l^{24}$ in sedated and paralysed morbidly obese subjects suggested that high intra-abdominal pressures may have an important effect on mechanical properties of the respiratory system, but the methodology used did not allow their findings on operating lung volumes to be extrapolated to spontaneously breathing subjects.

Therefore, the aim of the present study was to undertake a comprehensive study to determine the 
factors contributing to impaired lung mechanics in obese but otherwise healthy people in both seated and supine postures.

\section{PATIENTS AND METHODS}

The study was approved by King's College Hospital local research ethics committee. We approached obese but otherwise healthy patients, usually attending for consideration of bariatric surgery, and normal subjects at King's College Hospital to participate. Each participant gave written informed consent. None of the participants was an active smoker, three of the obese and two of the normal subjects were ex-smokers, each one of them with a smoking history of less than 10 pack-years.

The methods used in this study have been established in clinical practice $;^{25-28}$ for a more detailed report on measurements of anthropometric data, lung function, dynamic compliance, pressures and electromyogram (EMG), please refer to the online supplement.

The ratio of oesophageal to mouth pressure measured during efforts against an occlusion (Poes:Pmouth) was used to verify correct placement of the oesophageal balloon catheter. It was $1.05(0.06)$ seated in normal vs $1.01(0.08)$ in obese subjects $(p=0.299)$ and $0.98(0.05)$ in the normal vs $0.93(0.04)$ in the obese when supine $(\mathrm{p}=0.039)$.

\section{Breathing manoeuvres}

Resting breathing and recording of pressure volume curves

Resting breathing was recorded for 2 min while relaxed, seated in an arm chair and for 2 min lying supine on a bed, the head resting on a pillow, wearing a noseclip, breathing through a flanged mouthpiece connected to a pneumotachograph. The subjects then performed three TLC manoeuvres through a spirometer (Morgan, Massachusetts, USA), followed by brief and stepwise occlusions and openings of the mouthpiece at different lung volumes, to obtain pressure-volume (PV) curves over the complete expiratory vital capacity (figure 1 ). The measurements were repeated 3-5 times when seated and 3-5 times when supine. In addition, as the spirometer provided a closed system, we were able, as the subjects moved from the seated to the supine posture, to determine changes in FRC and TLC. For this purpose, subjects performed an inspiratory capacity (IC) manoeuvre seated and, allowing several tidal breaths to adjust for the new posture, another IC manoeuvre when reclined in a chair, tilted backwards with the body horizontal. They were then made to sit upright again to perform a third IC manoeuvre. Subjects stayed connected to the mouthpiece while undergoing this manoeuvre, and this enabled the measurement of differences in IC and TLC (figure 2). The manoeuvre was repeated 2-3 times.

\section{Statistical analysis}

We analysed data from all recorded PV curves. Mean and SD are reported for normally distributed data. Correlations are reported between variables using the $\mathrm{R}^{2}$-value. Group differences were compared using an unpaired t test, and changes in parameters when changing posture from the seated to the supine were analysed with paired t tests. Fisher's exact test was used to analyse categorical data (gender). Differences were considered to be of significance with a $\mathrm{p}<0.05 .^{29}$ For a more detailed report on the sample size calculation, please refer to the online supplement.



Figure 1 Breathing manoeuvre performed to generate the pressure-volume curves. EMG parasternal intercostals activity (top trace) and EMG abdominal muscles (second trace), muscle activity can be clearly identified in inspiration between the ECG artefacts. Inspiratory muscle activity declines until functional residual capacity (FRC) is reached and expiratory muscle activity then increases at lung volumes below FRC. X-axis indicates time in seconds. 
Figure 2 Simplified schematic illustration of lung volumes seated and supine in normal and obese subjects, expressed as litres (upper panel) and per cent predicted TLC (lower panel). Parameters are derived from tables 2 and 3. TLC, total lung capacity; IRV, inspiratory reserve volume; $V_{t}$, tidal volume; ERV, expiratory reserve volume; RV, residual volume.


\section{RESULTS}

\section{Subjects}

We studied nine obese subjects (mean (SD) body mass index (BMI) $46.8(17.2) \mathrm{kg} / \mathrm{m}^{2}$ ) and nine normal weight controls (mean (SD) BMI $23.2(1.6) \mathrm{kg} / \mathrm{m}^{2}$ ). Three of the obese subjects and two of the control subjects were ex-smokers $(<10$ packyears), but all had a normal $\mathrm{FEV}_{1} / \mathrm{FVC}$ ratio. The two groups were matched for gender, age and were similar in height. The obese group were more breathless than normals. Waist circumference correlated with the amount of fat tissue deposited in the abdominal wall (abdominal skin fold double layer vs waist circumference; $\mathrm{R}^{2}=0.69, \mathrm{p}<0.001$; table 1 ).

\section{Spirometry and lung volumes}

$\mathrm{FEV}_{1}$ and FVC (L) were reduced in the obese subjects. Obese subjects had a smaller TLC, expressed as per cent predicted, and a smaller vital capacity. IC (defined as TLC minus FRC) was not different between the groups when seated. Seated FRC was reduced in the obese, both measured in litres and expressed as FRC/TLC. Although FRC was larger in the supine posture when expressed as volume (in litres) in normals, it was similar between the groups when expressed as per cent of TLC. RV in absolute volume (litres) was similar in both groups, but RV/TLC in the obese subjects was higher. Expiratory reserve volume (ERV) was significantly reduced in the obese (table 2; figure 2). Waist circumference correlated negatively with FRC $\left(\mathrm{R}^{2}=0.47\right.$, $\mathrm{p}<0.01$ ) and with TLC, expressed as per cent predicted $\left(\mathrm{R}^{2}=0.41, \mathrm{p}<0.01\right.$; figures 3 and 4$)$.

Reduction in TLC when supine was small and similar in normal and obese groups $(-0.24(0.08) \mathrm{L}$ in normal vs -0.25 $(0.08) \mathrm{L}$ in obese subjects, $\mathrm{p}=0.70)$. When supine, IC decreased only in the obese subjects and FRC remained constant in both postures in obese subjects. In normal subjects, IC increased when changing to the supine posture, despite a decrease in TLC, with a fall of approximately $500 \mathrm{~mL}$ in FRC with change in posture (table 2, figure 2). In contrast, IC did not change in the obese group and five obese subjects had no measurable ERV when supine.

\section{Dynamic and static lung compliance}

Tidal volume $\left(\mathrm{V}_{\mathrm{t}}\right)$ was similar between the groups and did not change significantly with posture. Seated dynamic lung compliance, when expressed as \%predicted TLC in order to correct for differing height and gender, was not different between groups. With change in posture to the supine position, dynamic compliance decreased in both groups (table 3; figures 3 and 4). 
Table 1 Anthropometry and spirometry

\begin{tabular}{|c|c|c|c|}
\hline Parameter & $\begin{array}{l}\text { Normal } \\
\text { group }\end{array}$ & $\begin{array}{l}\text { Obese } \\
\text { group }\end{array}$ & $p$ Value \\
\hline Age (year) & $38(11)$ & $45(13)$ & n.s. \\
\hline Gender (m:f) & $5: 4$ & $4: 5$ & n.s. \\
\hline Height (m) & $1.75(0.10)$ & $1.65(0.12)$ & 0.094 \\
\hline Weight (kg) & $71.4(12.5)$ & $124.9(36.0)$ & 0.001 \\
\hline BMI $\left(\mathrm{kg} / \mathrm{m}^{2}\right)$ & $23.2(1.6)$ & $46.8(17.2)$ & 0.001 \\
\hline Neck circumference $(\mathrm{cm})$ & $35.1(2.4)$ & $43.4(3.2)$ & $<0.001$ \\
\hline Waist (cm) & $81.3(9.3)$ & $122.8(18.9)$ & $<0.001$ \\
\hline Hip (cm) & $95.9(5.6)$ & $127.8(20.6)$ & $<0.001$ \\
\hline Waist:hip ratio & $0.85(0.07)$ & $0.96(0.09)$ & 0.006 \\
\hline MRC Dyspnoea Score (points) & $1.0(0.0)$ & $2.4(1.2)$ & 0.003 \\
\hline $\mathrm{FEV}_{1}(\mathrm{~L})$ & $4.4(1.0)$ & $3.0(1.5)$ & 0.033 \\
\hline $\mathrm{FEV}_{1}$ (\%predicted) & $119.6(17.8)$ & $97.4(24.7)$ & 0.044 \\
\hline FVC (L) & $5.3(1.3)$ & $3.7(1.8)$ & 0.043 \\
\hline FVC (\%predicted) & $125.2(17.3)$ & $96.8(19.7)$ & 0.005 \\
\hline $\mathrm{FEV}_{1} / \mathrm{FVC}(\%)$ & $82.5(4.2)$ & $79.6(7.3)$ & 0.325 \\
\hline $\begin{array}{l}\text { Sagittal abdominal diameter/SAD } \\
(\mathrm{cm})\end{array}$ & $21.1(2.0)$ & $33.3(7.7)$ & $<0.001$ \\
\hline Delta $S A D_{\text {inspiration }}(\mathrm{cm})$ & $2.7(1.0)$ & $2.6(0.3)$ & 0.649 \\
\hline Double skinfold abdomen $(\mathrm{mm})$ & $14.4(5.3)$ & $47.2(19.6)$ & $<0.001$ \\
\hline
\end{tabular}

A calculated mid-range slope of the static expiratory PV curves revealed no significant difference between the groups within the range of $50-60 \%$ predicted TLC, but there was reduced compliance between 60 and $70 \%$ of predicted TLC in the obese subjects, seated and supine (table 4; for individual PV curves, please review the online supplement).

\section{End-expiratory pressures at FRC during tidal breathing}

At FRC, end-expiratory oesophageal pressures were higher in the obese group when seated and supine. Both groups revealed a similar increase (mean change of 7.4 vs $8.8 \mathrm{~cm} \mathrm{H}_{2} \mathrm{O}$ ) in the mean oesophageal pressure when changing to the supine posture. End-expiratory gastric pressures were higher in the obese group, seated and supine. However, intra-abdominal pressures fell when changing from the seated posture to the supine in both groups by around $5 \mathrm{~cm} \mathrm{H}_{2} \mathrm{O}$. End-expiratory transdiaphragmatic pressure was not different between the two groups, sitting and supine, and was consistent with pressure equilibration between the abdominal and thoracic compartment in supine posture. Transpulmonary pressures were significantly lower at end-expiration in obese subjects, but fell with recumbency by a similar amount in both groups (table 3 ).

\section{Pressures during maximal inspiratory effort}

Pressure changes associated with full lung inflation (IC manoeuvre) revealed no significant differences between the two groups in intrathoracic (Poes), intra-abdominal (Pgas) or transdiaphragmatic (Pdi) pressures. However, the transpulmonary pressure gradient was reduced in the obese group at TLC when seated and supine (table 4).

\section{Respiratory muscle tests}

Inspiratory muscle strength, as assessed by a PImax manoeuvre, was reduced in both postures in the obese subjects compared with normals (table 4$).^{30}$

\section{Correlations}

There was a moderate positive correlation between end-expiratory gastric pressure and waist circumference $\left(\mathrm{R}^{2}=0.52\right.$ seated, $\mathrm{R}^{2}=0.60$ supine, $\left.\mathrm{p}<0.01\right)$. Similarly, the BMI was positively correlated to end-expiratory gastric pressure, seated $\left(\mathrm{R}^{2}=0.43\right.$, $\mathrm{p}<0.01)$ and supine $\left(\mathrm{R}^{2}=0.66, \mathrm{p}<0.01\right)$. End-expiratory gastric pressure was negatively correlated with FRC $\left(\mathrm{R}^{2}=0.59\right.$ seated, $\mathrm{R}^{2}=0.67$ supine, $\left.\mathrm{p}<0.01\right)$ and ERV $\left(\mathrm{R}^{2}=0.47\right.$ seated, $\mathrm{R}^{2}=0.28$ supine, $\mathrm{p}<0.01$; both in percent of TLC), and therefore the more obese patients had higher gastric pressures and lower FRC and ERV.

End-expiratory oesophageal pressures were related to end-expiratory gastric pressures $\left(\mathrm{R}^{2}=0.48\right.$ seated; $\mathrm{R}^{2}=0.68$ supine, $\mathrm{p}<0.01)$ and, therefore, also correlated to waist circumference $\left(\mathrm{R}^{2}=0.48\right.$ seated; $\mathrm{R}^{2}=0.61$ supine, $\left.\mathrm{p}<0.01\right)$ and $\mathrm{BMI}$ $\left(\mathrm{R}^{2}=0.51\right.$ seated; $\mathrm{R}^{2}=0.62$ supine, $\left.\mathrm{p}<0.01\right)$.

\section{DISCUSSION}

The main findings of the current study are that obese people, particularly when supine, have raised gastric and oesophageal pressures and associated dramatic reductions of FRC and ERV. The high oesophageal pressure imposes a threshold load on inspiration. The obese individual has the option of breathing at low lung volumes, with limited tidal volume, or increasing $V_{t}$ by adopting a breathing position on a higher part of the PV curve. The reduced compliance when breathing at lower volumes, as well as the inspiratory threshold load, increase the work of breathing, reflected in elevated levels of neural respiratory drive. ${ }^{12}$
Figure 3 Pressure-volume (PV) curves seated of a normal (N9, male, 66 years, $1.72 \mathrm{~m}$, body mass index (BMI) $23.3 \mathrm{~kg} / \mathrm{m}^{2}$; filled circles) and matched obese $(01$, male, 60 years, $1.73 \mathrm{~m}, \mathrm{BMI} 34.4 \mathrm{~kg} / \mathrm{m}^{2}$; open circles) subject. Functional residual capacity (FRC) levels and dynamic compliance are indicated by bold grey bars. The PV curve in the obese is restricted in lung volume and diminished in slope, the FRC is low. Despite the differences in the slope of the static PV curves, the dynamic compliance, illustrated by the diagonal grey bars, is not substantially different between the obese and normal subject.




Figure 4 Pressure-volume curves supine of a normal (N9, filled circles) and matched obese (01, open circles) subject. Compared with the seated posture, the slope of the curves is diminished, in the obese functional residual capacity approximates residual volume. Dynamic compliance is lower than when seated and more different between obese and normal subject.

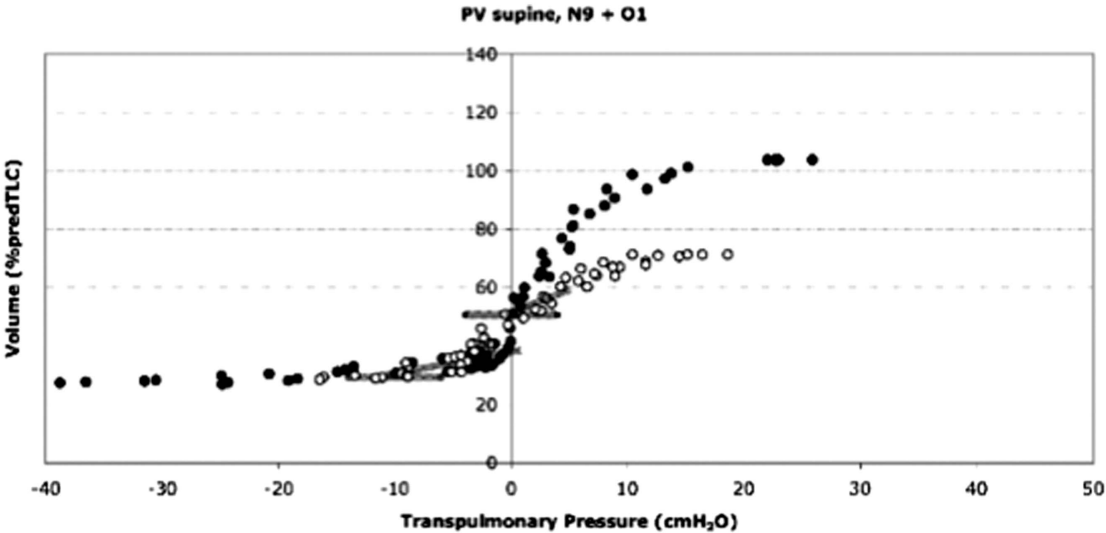

Increased intra-abdominal pressures cause a threshold load on the diaphragm at end-expiration that needs to be overcome prior to any diaphragmatic movement. This leads to higher than normal intrathoracic pressures in obese subjects, particular at end-expiration when transdiaphragmatic pressures indicate a relaxed diaphragm, and it increases further with supine posture. High oesophageal pressures are associated with low FRC and reduced ERV in obesity as they diminish transpulmonary pressures during tidal breathing.

Postural changes in intra-abdominal and intrathoracic pressures become more important in obesity due to reduced ERV and the higher threshold load on the diaphragm. Work of breathing in obesity, which is already high when seated, further increases with recumbency, caused by a disadvantageous impact of gravity. There is equilibration of the high intra-abdominal with intrathoracic pressures because the diaphragm is relatively inactive (table 3).

\section{Significance of the findings}

Previously, our group studied neural respiratory drive in obesity and found it to be raised. ${ }^{12}$ In that study, we also measured oesophageal and gastric pressures, seated and supine, confirming increased levels of gastric and oesophageal pressures in wakeful breathing subjects, but the study did not measure lung volumes or transpulmonary pressures.

Data on oesophageal pressures and spirometry in wakeful spontaneously breathing overweight and obese subjects have been published by Owens et al. ${ }^{31}$ Although their subjects were less obese (BMI $33.3(5.7) \mathrm{kg} / \mathrm{m}^{2}$ ), they concluded that oesophageal pressure can be reliably measured in the seated and supine posture. However, they did not measure PV curves, abdominal pressures and lung compartments. In this context, it is of interest that Washko et $a l^{19}$ also assessed the change in transpulmonary pressure in healthy normal subjects that was associated with change in posture from the seated to the supine. They found that $\mathrm{P}_{\mathrm{L}}$ decreases by $7.0 \mathrm{~cm} \mathrm{H} \mathrm{H}_{2} \mathrm{O}$, in agreement with our finding that $\mathrm{P}_{\mathrm{L}}$ decreases by $7.4 \mathrm{~cm} \mathrm{H}_{2} \mathrm{O}$ with change in posture in the normal group and by $8.8 \mathrm{~cm} \mathrm{H}_{2} \mathrm{O}$ in the obese subjects.

Behazin et $a l^{23}$ studied obese and normal subjects supine, anaesthetised and paralysed perioperatively. They measured Poes at relaxation volume (Poes, rel) and found it to be above atmospheric pressure, 12.5 (3.9) $\mathrm{cm} \mathrm{H}_{2} \mathrm{O}$ in the obese and 6.9 (3.1) in the normal $(\mathrm{p}<0.0001)$ groups, comparable pressure levels to our findings in wakeful subjects breathing at FRC, supine (table 4). Similarly, the gastric pressures of the obese group in their study were within the range of our observations

Table 2 Total lung capacity and subdivisions, seated and supine

\begin{tabular}{|c|c|c|c|c|c|c|}
\hline \multirow{2}{*}{$\begin{array}{l}\text { Parameter } \\
\text { TLC (L) }\end{array}$} & \multirow{2}{*}{$\begin{array}{c}\text { Normal group, seated } \\
6.8(1.7)\end{array}$} & Obese group, seated & \multirow{2}{*}{$\begin{array}{c}\mathrm{p} \text { Value } \\
0.065\end{array}$} & Normal group, supine & \multirow{2}{*}{$\begin{array}{l}\text { Obese group, supine } \\
4.8(1.9)\end{array}$} & \multirow{2}{*}{$\frac{p \text { Value }}{0.058}$} \\
\hline & & $5.1(1.9)$ & & $6.5(1.7)$ & & \\
\hline TLC (\%pred) & $104.4(12.3)$ & $88.6(16.9)$ & 0.033 & $\mathrm{~N} / \mathrm{A}$ & $\mathrm{N} / \mathrm{A}$ & N/A \\
\hline VC (L) & $5.3(1.3)$ & $3.6(1.8)$ & 0.035 & $5.2(1.2)$ & $3.4(1.8)$ & 0.030 \\
\hline FRC (L) & $3.2(0.9)$ & $1.8(0.5)$ & 0.002 & $2.7(0.7)$ & $1.8(0.4)$ & 0.004 \\
\hline FRC/TLC (\%) & $46.9(4.6)$ & $37.5(6.9)$ & 0.004 & $41.5(4.3)$ & $39.4(7.7)$ & 0.477 \\
\hline ERV (L) & $1.7(0.6)$ & $0.4(0.4)$ & $<0.001$ & $1.1(0.3)$ & $0.3(0.4)$ & $<0.001$ \\
\hline ERV/TLC (\%) & $25.8(6.3)$ & $6.1(6.4)$ & $<0.001$ & $17.5(6.4)$ & $4.2(6.4)$ & $<0.001$ \\
\hline RV (L) & $1.5(0.6)$ & $1.5(0.3)$ & 0.979 & $1.4(0.6)$ & $1.4(0.3)$ & 0.872 \\
\hline RV/TLC (\%) & $21.2(4.9)$ & $31.4(10.1)$ & 0.015 & $20.4(5.1)$ & $32.2(11.1)$ & 0.010 \\
\hline IC (L) & $3.6(0.9)$ & $3.2(1.4)$ & 0.564 & $4.1(1.2)$ & $3.3(1.5)$ & 0.227 \\
\hline \multicolumn{2}{|c|}{ Change of volumes with recumbency } & \multicolumn{2}{|c|}{ Normal group } & \multicolumn{2}{|c|}{ Obese group } & $\mathrm{p}$ Value \\
\hline$\Delta \mathrm{TLC}(\mathrm{L})$ & & \multicolumn{2}{|c|}{$-0.24(0.08)$} & \multicolumn{2}{|c|}{$-0.25(0.08)$} & 0.695 \\
\hline$\Delta \mathrm{IC}(\mathrm{L})$ & & \multicolumn{2}{|c|}{$0.36(0.59)$} & \multicolumn{2}{|c|}{$-0.19(0.15)$} & $<0.016$ \\
\hline$\triangle \mathrm{FRC}(\mathrm{L})$ & & \multicolumn{2}{|c|}{$-0.51(0.42)$} & \multicolumn{2}{|c|}{$-0.04(0.13)$} & 0.05 \\
\hline
\end{tabular}

Lung volumes in obese and normal subjects, seated and supine. $\Delta$ indicates the change of volume with recumbency (+, increased volume in supine posture; - , loss of volume in supine posture).

ERV, expiratory reserve volume; FRC, functional residual capacity; IC, inspiratory capacity; RV, residual volume; TLC, total lung capacity. 
Table 3 Tidal breathing and dynamic compliance

\begin{tabular}{|c|c|c|c|c|c|c|}
\hline Parameter & Normal group, seated & Obese group, seated & p Value & Normal group, supine & Obese group, supine & p Value \\
\hline$V_{t}(L)$ & $0.64(0.14)$ & $0.63(0.10)$ & 0.584 & $0.61(0.13)$ & $0.67(0.12)$ & 0.317 \\
\hline $\mathrm{V}_{\mathrm{t}}(\%$ predTLC) & $9.3(1.4)$ & $11.5(2.1)$ & 0.017 & $9.6(1.8)$ & $12.2(2.8)$ & 0.031 \\
\hline Cdyn $\left(\mathrm{L} / \mathrm{cm} \mathrm{H} \mathrm{H}_{2} \mathrm{O}\right)$ & $0.194(0.070)$ & $0.142(0.049)$ & 0.087 & $0.135(0.037)^{*}$ & $0.105(0.024)^{*}$ & 0.057 \\
\hline Cdyn (\%predTLC/cm H $\mathrm{H}_{2} \mathrm{O}$ ) & $3.0(1.0)$ & $2.6(1.0)$ & 0.398 & $2.1(0.4)^{*}$ & $2.0(0.7)^{\star *}$ & 0.545 \\
\hline Poes, ee $\left(\mathrm{cm} \mathrm{H}_{2} \mathrm{O}\right)$ & $-2.0(3.5)$ & $5.2(6.9)$ & 0.013 & $5.4(3.1)^{* * *}$ & $14.0(8.0)^{* *}$ & 0.008 \\
\hline Pgas, ee $\left(\mathrm{cm} \mathrm{H}_{2} \mathrm{O}\right)$ & $12.1(6.2)$ & $19.1(4.7)$ & 0.015 & $7.1(2.6)^{*}$ & $14.3(5.7)^{*}$ & 0.003 \\
\hline Pdi, ee $\left(\mathrm{cm} \mathrm{H}_{2} \mathrm{O}\right)$ & $14.1(5.3)$ & $13.9(5.1)$ & 0.933 & $1.7(2.8)^{* * *}$ & $0.2(5.3)^{* * *}$ & 0.461 \\
\hline $\mathrm{P}_{\mathrm{L}}$, ee $\left(\mathrm{cm} \mathrm{H}_{2} \mathrm{O}\right)$ & $2.9(1.4)$ & $-4.7(5.0)$ & $<0.001$ & $-4.6(2.5)^{* * *}$ & $-11.6(5.0)^{* * *}$ & 0.002 \\
\hline
\end{tabular}

Lung volumes, dynamic compliance and end-expiratory pressures at FRC in the thoracic and abdominal compartment for obese and normal subjects, seated and supine.

${ }^{*} p<0.05,{ }^{* *} p<0.01,{ }^{* * *} p<0.001$ for the comparison of associated changes with posture

cdyn, dynamic compliance; FRC, functional residual capacity; Pdi, ee, transdiaphragmatic pressure at end-expiration; Pgas, ee, gastric pressure at end-expiration; $P_{\mathrm{L}}$, ee, transpulmonary

pressure at end-expiration; Poes, ee, oesophageal pressure at end-expiration; TLC, total lung capacity; $\mathrm{V}_{\mathrm{t}}$, tidal volume.

considering that our obese group had a slightly higher BMI (11.5 (2.8) $\mathrm{cm} \mathrm{H}_{2} \mathrm{O}$ in their data compared with 14.3 (5.7) $\mathrm{cm} \mathrm{H}_{2} \mathrm{O}$ in obese subjects supine at FRC in our study).

Intra-abdominal hypertension has been identified as an important issue in obesity that potentially impacts on ventilation in the perioperative setting. ${ }^{32} 33$ Pelosi et l $^{24}$ investigated the respiratory system in sedated and paralysed morbidly obese subjects. They included eight subjects (BMI $48.7(7.8) \mathrm{kg} / \mathrm{m}^{2}$ ) with a similar age (38 (12) years) to our groups and compared respiratory mechanics in supine posture with a historic normal control group. FRC was remarkably reduced in obesity. Changes in mechanical properties secondary to reduced lung volumes were found to be caused by an excessive and unopposed intra-abdominal pressure $\left(24.0(2.2) \mathrm{cm} \mathrm{H}_{2} \mathrm{O}\right)$, as measured with a transurethral bladder catheter and the bladder being filled with $100 \mathrm{~mL}$ of saline solution. However, the study $\operatorname{design}^{24}$ did not allow them to measure lung volumes simultaneously during wakeful breathing nor did it consider the upright posture. Our study analysed spontaneous respiratory muscle function opposing the high intra-abdominal pressure in nonsedated and non-paralysed spontaneously breathing obese subjects, seated and supine.

Our data confirm differences in compliance related to posture $^{23} 34$ and differences in lung volumes associated with obesity and posture. $^{8} 1219$ The mid-range compliance at 50$60 \%$ of TLC was not different between the groups, but tended to fall with recumbency. At a higher lung volume of $60-70 \%$ TLC, the compliance was reduced in obese subjects, seated and supine, and tended to fall in this group with recumbency. The difference between the groups was explained, to some extent, by the plateau of the PV curve in the restricted obese subjects when approaching TLC. However, a reduced compliance with change in posture to the supine might be caused by multiple factors, including a drop in lung volumes, the increased impact of abdominal pressures on the thoracic cavity, a change in the chest configuration and an increased venous return. These results provide a likely explanation why patients with obesity benefit from CPAP when supine ${ }^{12} 35$; CPAP counterbalances the high intrathoracic and intra-abdominal pressures and elevates the FRC levels. However, questions regarding the proposed model of lung 'hypoinflation' in obesity remain, ${ }^{16}{ }^{18}$ and further larger studies distinguishing between obese subjects with and without restriction may provide additional insight into the pathophysiological origin of intra-abdominal hypertension and its impact on respiratory function and symptoms in obesity. The variability of the relationship between static and dynamic compliance in obese subjects requires further investigations, including whether or not it could be caused by chronic changes to the small airways or lung parenchyma.

\section{Clinical implications}

The impact of obesity, particularly morbid obesity, on the respiratory system has long been observed in the clinical setting. Obese subjects are more breathless and at risk of developing respiratory failure by day and sleep-disordered breathing by

Table 4 Static pressures during maximal inspiratory effort and static expiratory compliance

\begin{tabular}{|c|c|c|c|c|c|c|}
\hline Parameter & $\begin{array}{l}\text { Normal group, } \\
\text { seated }\end{array}$ & $\begin{array}{l}\text { Obese group, } \\
\text { seated }\end{array}$ & $\begin{array}{l}p \\
\text { Value }\end{array}$ & $\begin{array}{l}\text { Normal group, } \\
\text { supine }\end{array}$ & $\begin{array}{l}\text { Obese group, } \\
\text { supine }\end{array}$ & $\begin{array}{l}\mathrm{p} \\
\text { Value }\end{array}$ \\
\hline Poes at $\operatorname{TLC}\left(\mathrm{cm} \mathrm{H}_{2} \mathrm{O}\right)$ & $-42.8(10.9)$ & $-34.9(10.5)$ & 0.140 & $-43.3(13.9)$ & $-42.2(10.7)$ & 0.846 \\
\hline Pgas at TLC $\left(\mathrm{cm} \mathrm{H}_{2} \mathrm{O}\right)$ & $28.9(25.0)$ & $18.1(10.9)$ & 0.206 & $28.5(22.0)$ & $16.4(13.7)$ & 0.180 \\
\hline Pdi at TLC $\left(\mathrm{cm} \mathrm{H}_{2} \mathrm{O}\right)$ & $54.1(19.5)$ & $50.5(17.6)$ & 0.682 & $64.8(24.0)^{*}$ & $52.7(16.7)$ & 0.235 \\
\hline$P_{L, \max }$ at $\operatorname{TLC}\left(\mathrm{cm} \mathrm{H}_{2} \mathrm{O}\right)$ & $32.2(2.8)$ & $23.7(7.4)$ & 0.033 & $31.7(2.5)$ & $25.3(7.5)$ & 0.028 \\
\hline PImax at FRC $\left(\mathrm{cm} \mathrm{H}_{2} \mathrm{O}\right)$ & $109.9(41.8)$ & $72.2(30.1)$ & 0.043 & $96.7(32.9)^{*}$ & $55.2(26.0)^{* *}$ & 0.009 \\
\hline $\begin{array}{l}\mathrm{C}_{\mathrm{L}, \text { stat }} \text { slope } 50-60 \% \text { pred TLC (\%pred TLCI } \\
\mathrm{cm} \mathrm{H}_{2} \mathrm{O} \text { ) }\end{array}$ & $7.0(3.4)$ & $6.1(5.0)$ & 0.682 & $4.1(2.0)^{*}$ & $3.6(2.2)^{*}$ & 0.617 \\
\hline $\begin{array}{l}\mathrm{C}_{\mathrm{L}, \mathrm{stat}} \text { slope } 60-70 \% \text { predTLC (\%pred TLCl } \\
\mathrm{cm} \mathrm{H} \mathrm{H}_{2} \mathrm{O} \text { ) }\end{array}$ & $8.4(5.1)$ & $3.8(1.7)$ & 0.023 & $6.6(4.8)$ & $2.9(1.2)^{*}$ & 0.040 \\
\hline
\end{tabular}


night compared with their matched peer group. Our findings set out the importance of obesity in the clinical setting in the fields of respiratory, sleep and critical care medicine. In particular, the negative effect of the supine posture should be considered when assessing the bed-bound patient or deciding ventilator settings.

Hypothetically, it could be speculated that interventions that reduce intra-abdominal pressures would improve respiratory function in the obese, with an impact on sleep-disordered breathing, breathlessness and respiratory failure, as well as reducing perioperative risks.

Our findings may also provide an explanation for an observation that occurs with increasing frequency in our clinical practice. Specifically the authors have seen overweight patients with seated hypoxia and restrictive defects where the a-A gradient narrows with exercise. We speculate that such patients are moved, as the minute ventilation increases, to a steeper part of the PV curve, thus improving ventilation-perfusion matching. This is consistent with the findings by O'Donnell et al that the exercise capacity of severely obese patients is less impaired than expected. ${ }^{9}$ Such findings are important in the context of exercise rehabilitation programmes for patients with severe obesity.

\section{Critique of the method}

Careful matching is essential in studies with small groups. We sought to compare similar groups with regard to age, gender and height. There were small differences in lung volumes, and it could be argued that expressing all lung volumes as per cent predicted could be more helpful for data presentation. However, this is difficult because there are no standard reference volumes for supine posture that could have been used. We have therefore chosen to describe volumes in absolute units (L) and, where appropriate, in per cent predicted. Nonetheless, we appreciate that the gender difference in lung volumes, with lower expected TLC in females, may have led to the assumption that there is no gender difference in dynamic compliance between our groups. To address this limitation for which our study was not powered, we have presented the PV slopes for each individual male and female subject (see online supplementary figures E1 and E2). We accept that larger studies may be required to fully address the relationship between obesity and dynamic compliance. In addition, extreme or morbid obesity has not been explicitly considered when generating reference equations for lung volumes and the current obesity rates in the UK would impact on what is considered 'normal lung function'; approximately $25 \%$ of adults in the UK are obese. This explains why existing reference equations might need to be interpreted with caution if they have not been updated; the respective cohort (eg, ECCS) might have evolved, an effect called the 'cohort effect'.

This study focused on pressure gradients as the driving force for lung inflation. To our knowledge, absolute pressures and pressure gradients do not require correction or normalisation in a different way than has been achieved by matching our groups and, therefore, the impact of small differences between the groups in height and lung volumes may be less important.

The measurement of PImax is a volitional manoeuvre and the results, indicating that obese subjects may have been weaker, have to be interpreted with caution, particularly because previous studies failed to show a difference. ${ }^{12}$ In the current dataset, although obese subjects were weaker than expected, they were not weak compared with published data. ${ }^{25} 30$ The PV curves indicated available pressure generation capacity when TLC was reached in the obese, which makes it unlikely that restriction is caused by weakness. Therefore, the specific cause for the restriction in TLC observed in the obese remains unclear.

\section{Conclusion}

Increased intra-abdominal pressure and the consequent increased intrathoracic pressure in obese subjects reduce FRC and ERV. In consequence, patients must either limit $V_{t}$ or breathe on a less compliant part of the PV curve, thereby increasing their work of breathing, which is already elevated due to the inspiratory threshold load caused by high intrathoracic pressures. The reduced FRC and ERV is an important abnormality of pulmonary mechanics in obesity.

The clinical management of severely obese patients is helped by our increased understanding of intra-abdominal hypertension and the associated reduced lung volumes.

Acknowledgements We gratefully acknowledge the support and help of $\mathrm{Mr}$ Simon Ward and Mark Unstead, Lung Function Laboratory, Royal Brompton Hospital.

Contributors Involvement in the conception, hypotheses delineation and design of the study: JS, MIP and JM. Acquisition of the data or the analysis and interpretation of such information: JS, AL, MIP and JM. Writing the article or substantial involvement in its revision prior to submission: JS, NH, MIP and JM.

Funding The research was supported by the National Institute for Health Research (NIHR) Biomedical Research Centre based at Guy's and St Thomas' NHS Foundation Trust and King's College London. MIP's salary is part funded by the NIHR Respiratory Biomedical Research Unit at the Royal Brompton and Harefield NHS trust and Imperial College.

\section{Competing interests None.}

Ethics approval King's College Hospital, London Local Research Ethics Committee. Provenance and peer review Not commissioned; externally peer reviewed.

Data sharing statement The raw data recordings are stored at King's College Hospital and have been accessed by all coauthors for analysis.

\section{REFERENCES}

1 Flegal KM, Carroll MD, Kuczmarski RJ, et al. Overweight and obesity in the United States: prevalence and trends, 1960-1994. Int J Obes Relat Metab Disord 1998;22:39-47

2 Flegal $\mathrm{KM}$, Carroll MD, Ogden $\mathrm{CL}$, et al. Prevalence and trends in obesity among US adults, 1999-2000. JAMA 2002;288:1723-7.

3 Sturm R. Increases in morbid obesity in the USA: 2000-2005. Public Health 2007;121:492-6

4 Franks PW, Hanson RL, Knowler WC, et al. Childhood obesity, other cardiovascular risk factors, and premature death. N Engl J Med 2010;362:485-93.

5 Ray CS, Sue DY, Bray G, et al. Effects of obesity on respiratory function. Am Rev Respir Dis 1983;128:501-6.

6 Jones RL, Nzekwu MM. The effects of body mass index on lung volumes. Chest 2006;130:827-33.

7 Hackney JD, Crane MG, Collier CC, et al. Syndrome of extreme obesity and hypoventilation: studies of atiology. Ann Intern Med 1959;51:541-52.

8 Yap JCH, Watson RA, Gilbey S, et al. Effects of posture on respiratory mechanics in obesity. J App/ Physiol 1995;79:1199-205.

9 Ofir D, Laveneziana $\mathrm{P}$, Webb KA, et al. Ventilatory and perceptual responses to cycle exercise in obese women. J App/ Physiol 2007;102:2217-26.

10 Tucker $\mathrm{DH}$, Sieker $\mathrm{HO}$. The effect of change in body position on lung volumes and intrapulmonary gas mixing in patients with obesity, heart failure and emphysema. Am Rev Respir Dis 1960;82:781-91.

11 Sampson MG, Grassino A. Neuromechanical properties in obese patients during carbon dioxide rebreathing. Am J Med 1983;75:81-90.

12 Steier J, Jolley C, Seymour J, et al. Neural respiratory drive in obesity. Thorax 2009;64:719-25

13 Sin DD, Jones RL, Man SF. Obesity is a risk factor for dyspnea but not for airflow obstruction. Arch Intern Med 2002;162:1477-81.

14 Olson AL, Zwillich CW. The obesity hypoventilation syndrome. Am J Med 2005;118:948-56.

15 Rochester DF, Enson Y. Current concepts in the pathogenesis of the obesity-hypoventilation syndrome. Am J Med 1974;57:402-20.

16 Druz ASS, Sharp JT. Activity of respiratory muscles in upright and recumbent humans. J App/ Physiol 1981;51:1552-61.

17 Allen SM, Hunt B, Green M. Fall in vital capacity with posture. $\mathrm{Br} J$ Dis Chest 1985:79:267-71. 
18 Sharp JT, Druz WS, Kondragunta VR. Diaphragmatic responses to body position changes in obese patients with obstructive sleep apnea. Am Rev Respir Dis 1986;133:32-7.

19 Washko GR, O'Donnell CR, Loring SH. Volume-related and volume-independent effects of posture on esophageal and transpulmonary pressures in healthy subjects. J Appl Physiol 2006;100:753-8.

20 Craig DB, Wahba WM, Don HF, et al. "Closing volume" and its relationship to gas exchange in seated and supine positions. J App/ Physiol 1971;31:717-21.

21 Farebrother MJB, McHardy GJR, Munro JF. Relationship between pulmonary gas exchange and closing volume before and after substantial weight loss in obese subjects. BMJ 1974;3:391-3.

22 Pankow W, Podszus T, Gutheil T, et al. Expiratory flow limitation and intrinsic positive end-expiratory pressure in obesity. J Appl Physiol 1998;85:1236-43.

23 Behazin $\mathrm{N}$, Jones $\mathrm{SB}$, Cohen $\mathrm{Rl}$, et al. Respiratory restriction and elevated pleural and esophageal pressures in morbid obesity. J App/ Physiol 2010;108:212-18.

24 Pelosi P, Croci M, Ravagnan I, et al. Respiratory system mechanics in sedated, paralyzed, morbidly obese patients. J App/ Physiol 1997;82:811-18.

25 American Thoracic Society/European Respiratory Society. ATS/ERS joint statement on respiratory muscle testing. Am J Respir Crit Care Med 2002;166:518-624.

26 British Thoracic Society. Guidelines for the measurement of respiratory function. Respir Med 1994;88:165-94.
27 Miller MR, Hankinson J, Brusasco V, et al. ATS/ERS task force. Standardisation of spirometry. Eur Respir J 2005;26:319-38.

28 Wanger J, Clausen JL, Coates $A$, et al. Standardisation of the measurement of lung volumes. Eur Respir J 2005;26:511-22.

29 Petrie A, Sabin C. Medical statistics at a glance. 2nd edn. Oxford: Blackwell Publishing Itd, 2005.

30 Steier J, Kaul S, Seymour J, et al. The value of multiple tests of respiratory muscle strength. Thorax 2007;62:975-80.

31 Owens RL, Campana LM, Hess L, et al. Sitting and supine esophageal pressures in overweight and obese subjects. Obesity (Silver Spring) 2012;20:2354-60.

32 Kirkpatrick AW, Pelosi P, De Waele JJ, et al. Clinical review: intra-abdominal hypertension: does it influence the physiology of prone ventilation? Crit Care 2010;14:232.

33 Pelosi $\mathrm{P}$, Luecke $T$, Rocco PR. Chest wall mechanics and abdominal pressure during general anaesthesia in normal and obese individuals and in acute lung injury. Curr Opin Crit Care 2011;17:72-9.

34 Estenne M, Yernault J-C, De Troyer A. Rib cage and diaphragm-abdomen compliance in humans: effects of age and posture. J Appl Physiol 1985;59:1842-8.

35 Pelosi P, Ravagnan I, Giurati G, et al. Positive end-expiratory pressure improves respiratory function in obese but not in normal subjects during anesthesia and paralysis. Anesthesiology 1999;91:1221-31. 